\title{
A Statistical Analysis of Alleged Sexual Assaults - Its Attributes and Aftermaths
}

\author{
Dr. S. Haflongbar ${ }^{1}$, Dr. B. Paul ${ }^{* 2}$, Dr. A. J. Patowary ${ }^{3}$ \\ ${ }^{1}$ PGT, ${ }^{2}$ Demonstrator, ${ }^{3}$ Associate Professor, \\ Department of Forensic Medicine, Gauhati Medical College \& Hospital, Guwahati
}

\section{*Corresponding author -}

\author{
Dr. Biswadeep Paul \\ Demonstrator, Department of Forensic Medicine \& Toxicology \\ Gauhati Medical College \& Hospital, Guwahati-32 \\ E-mail: drbiswadeeppaul @gmail.com
}

\begin{abstract}
Sex related offences against females are universal phenomena and constitute the most shocking reprehensible crime against conscience and morality and attack on human dignity and subjugation of the fairer sex. Psychiatric disturbances, venereal diseases, attempted suicides, unwanted pregnancies; lust murder and interpersonal violence constitute far flung consequences of sexual offences including sexual assault and violence. Inspite of stringent laws including POCSO, Sexual Harassment of Women at Workplace (Prevention, Prohibition and Redressal) Act and Criminal Law Amendment Act, sex crimes, rape and child abuse are on the rise. To analyse the antecedents and aftermaths, a statistical study was carried out on 93 female victims of alleged sexual offences who had consented for medical examination and study, on being brought to the Department. of Forensic Medicine, GMCH. Our study revealed that most of the victims were between 15 to18 years of age group with $30.11 \%$ of cases, $58.06 \%$ cases were Hindus, from urban areas with $52.69 \%$ cases, $48.39 \%$ were students, from lower socio-economic background with $73.12 \%$ cases and $79.57 \%$ were unmarried. Most of the sexual assaults occurred in the Month of September and $36.56 \%$ of the offenders were neighbours. A total of $60.22 \%$ cases had hymenal tears and $5.38 \%$ cases showed presence of spermatozoa in microscopic examination of vaginal, oral and anal smears. Comprehensive analysis of precipitating factors and evaluation of social, economic and psychological factors along with suggestion and remedial measures is the need of the hour for the benefit of the society in general and individuals in particular.
\end{abstract}

Keywords: Sexual offence, Sexual assault, Rape, Preventive and remedial interventions.

\section{Introduction}

Sex related offences are universal phenomena, which are taking place in every society. In common parlance, sexual offence constitutes the most shocking crime against conscience and morality. The legal definition and interpretation of the sexual offences is under constant change with changing times under the advice of sociologists and medico-scientists. According to American juriest, Ploscow Rape is a word of fearsome connotations. The term 'rape' brings out all the hostile, aggressive and protective instinct of the human male. The rapist is an object of universal detestation (Varma 1979). ${ }^{[13]}$

In 2002 the WHO defines sexual violence as: any sexual act, attempt to obtain an act, unwanted sexual comments or advances, or acts to traffic, or otherwise directed against a person's sexuality using coercion, by any person regardless of their relationship to the victim, in any setting, including but not limited to home and work. ${ }^{[1]}$ The incidence of sexual violence against women is increasing worldwide and the global statistics are shocking. Worldwide about $20 \%$ of women have been sexually abused in their childhood. ${ }^{[2]} \mathrm{A}$ high rate of sexual assault is found in other Asian countries as well. In Japan $60 \%$ of women suffer sexual violence while $25 \%$ of women in India and $53-62 \%$ of women in Bangladesh and $19 \%$ in North Carolina, United States are victimized at times. ${ }^{[3]}$

Though crime is prevalent in every country and society, most of them either goes undetected or unreported. As $\bullet$ per National Crime Records Bureau-(NCRB), New Delhi, a crime takes place every 17 seconds, among them one dowry death every 77 minutes, one crime against women every.3 minutes and finally one rape or sexual assault every 27 minutes. With above crime scenario, Forensic Medicine 


\section{International Journal of Innovative Research in Medical Science (IJIRMS) Volume 03 Issue 07 July 2018, ISSN: 2455-8737, Imp. Factor - $\underline{4.102}$ \\ Available online at - www.ijirms.in}

plays an important role in helping to prevent, early detection, providing expert medico legal and scientific reports at earliest, which will result in quick trial and instant administration of justice to victims.

\section{Aims \& Objectives:}

The aim of our study was to ascertain sexual violence in and around Guwahati city and to analyze the data with respect to epidemiological and demographics presentation, relationship between victim and accused, to know the age group commonly involved and necessary physical findings.

\section{Materials \& Methods:}

The present statistical study was conducted in the Department of Forensic Medicine of Gauhati Medical College \& Hospital for a period of 1 year from $1^{\text {st }}$ January to $31^{\text {st }}$ December 2015 based on the cases of alleged sexual assault victims reporting within 1 week of incident and consenting to medical examination. The data was collected from the police forwarding letter, history revealed by the victims, physical examination findings, dental data and radiological and laboratory investigations. Written informed consent of the victim or guardians was obtained and Participants Information Sheet along with proforma was prepared. All the findings were meticulously recorded, compiled, tabulated and analyzed. The main objective was to compile statistical epidemiological information, analyze the antecedents and aftermaths and subsequently formulate preventive interventions.

\section{Observations \& Results}

A total of 93 victims of alleged sexual assaults were examined in the department of Forensic Medicine of Gauhati Medical College \& Hospital during the study period from $1^{\text {st }}$ January to $31^{\text {st }}$ December 2015 . The age group between 15 to18 years of age contained the highest number of cases, 28(30.11\%), [Graph-1] Hindus were the majority with $54(58.06 \%)$ cases, [Graph-2] from urban areas in 49 (52.69\%) cases. [Graph-3] Most were educated up to primary level with 35 (37.63\%) cases [Graph-4] and students with $45(48.39 \%)$ cases [Graph-5] from the lower socio-economic group with $68(73.12 \%)$ cases. [Graph-6] Most of the victims were unmarried, a total of 74(79.57\%) cases. [Graph-7] 18(19.35\%) victims were depressed, $11(11.83 \%)$ cases were agitated and $12(12.91 \%)$ cases were aggrieved at the time of examination and in rest 52(55.91\%) cases there was no abnormality found. [Graph-8] Most of the incidence of sexual assault occurred in the Month of September, number of cases being 25 (26.88\%). [Graph-9] Maximum number of cases occurred in Summer and Autumn which constituted a total of 28 (30.11\%) cases [Graph-10] Most of the incidents- 36(38.71\%) took place in Victims Residence, while 31(33.33\%) cases took place in Offender's Residence. [Graph-11] Most vulnerable time was between 6:01 PM to 12:00 midnight consisting of 39(41.94\%) cases. [Graph-12] Maximum numbers of cases were brought within 3 days of incidence and out of them 42 (45.16\%) were brought for medical examination within 24 hours of incident. [Graph-13] Most of the offenders of sexual assault cases were known to the victims and amongst these 34(36.56\%) were neighbours. [Graph-14] Maximum cases $58(62.37 \%)$ attained Menarche and $2(2.15 \%)$ cases attained Menopause. Rest $33(35.48 \%)$ cases have not attained Menarche. [Graph-15] 92(98.92\%) of the cases were not pregnant at the time of examination. [Graph-16] In $82(88.17 \%)$, no stain was detected either on cloth or body. [Graph-17] Maximum number of cases 59(63.44\%) had injuries either in genitalia or body or in multiple parts of the body. 25(26.88\%) cases had injuries over genitalia, $20(21.51 \%)$ cases had injuries over body and 14(15.05\%) cases had injuries both over body and genitalia. [Graph-18] Most of the victims 56(60.22\%) had hymenal tears. $35(37.64 \%)$ cases had Old Tears and 15(16.13\%) had Carunculae Myrtiformes. Recent tear was seen in only 6 (6.45\%) cases. [Graph-19] 21 (22.58\%) cases had tears in 6 O'clock position which was most common and 12 O'clock position was the least common with no tears at all. In most of the cases tears were seen in multiple positions. [Graph20] Only 5(5.38\%) cases showed presence of spermatozoa and $8(8.60 \%)$ cases showed the presence of RBCs in the microscopic examination of vaginal smears / vulval / oral / anal swabs. [Graph-21]

\section{Discussion}

In the present study, most of the victims were children but with no age exemption. The youngest victim was a 3 years old child, the oldest being 80 years. The age group between 0 to 10 years of age contained the highest number of cases, $26(27.96 \%)$, followed by $24(25.81 \%)$ of cases in the age group of 12 to 16 years. The lowest number of cases, $2(2.15 \%)$ were reported in the age group of $25-45$ years. It is also observed that out of the cases, $69(74.2 \%)$ were below 18 (minor) years and $24(25.8 \%)$ cases were above 18 (major) years. The grouping of age is made conveniently in regard to the different legal age bars and age of the rape victims are made depending upon physical dental and radiological findings.

These findings are consistent with the findings of Voight (1972), ${ }^{[19]}$ Schiff (1978), ${ }^{[17]}$ Gradwohl (1976), ${ }^{[7]}$ Mohanty, N.K. et al (1981), ${ }^{[9]}$ who implicated that children were the most common victims. But in contrary Sukul et al (2009), ${ }^{[18]}$ Das P.P. (2009), ${ }^{[6]}$ found adults in the age group of 18 to 25 years as the most commonly involved groups. Increased incidence of rape cases among the younger population is due to the fact that, they are an easy prey being physically more weak could not offer much resistance, more accusable and more easily intimated. They were less mature hence wise in 


\section{International Journal of Innovative Research in Medical Science (IJIRMS) Volume 03 Issue 07 July 2018, ISSN: 2455-8737, Imp. Factor - $\underline{4.102}$ Available online at - www.ijirms.in}

life experiences, quickly flattered by attention and easily duped.

Hindus were the majority with $54(58.06 \%)$ cases similar to Bhowmik (2011), ${ }^{[5]}$ Tamuli (2013) $)^{[20]}$ and Baruah (2015) ${ }^{[4]}$ from urban areas with $49(52.69 \%)$ cases consistent with the findings of Roy Chowdhury (2008) ${ }^{[14]}$ but differing with Das (2009). ${ }^{[6]}$ The result also closely resembles the article appeared in Hindustan Times (1997) ${ }^{[21]}$ and educated up to primary level with $35(37.63 \%)$ cases and illiterate in $25(26.88 \%)$ cases similar to Tamuli $(2013)^{[20]}$ and Baruah $(2015){ }^{[4]}$

Students consisted $45(48.39 \%$ ) cases similar to Bhowmik $(2011)^{[5]}$ and Baruah (2015) ${ }^{[4]}$ from lower socio-economic background with $68(73.12 \%)$ cases similar to Das (2009). ${ }^{[6]}$ $74(79.57 \%)$ of the victims were unmarried consistent with the findings of Bhowmik (2011) ${ }^{[5]}$ and Tamuli (2013). ${ }^{[20]}$

On examination in $52(55.91 \%)$ cases there was no abnormality found. $18(19.35 \%)$ cases were depressed, 11 $(11.83 \%)$ cases were agitated and $12(12.91 \%)$ cases were aggrieved. This observation is also similar to the finding of Das (2009), ${ }^{[6]}$ who mentioned maximum cases had normal mental status.

Most incidents occurred in September, number of cases being $25(26.88 \%)$. Lowest number of such incidence occurred in the month of January and October with 3 (3.22\%) cases each consistent with the findings of Roy Chowdhury (2008), ${ }^{[14]}$ and Baruah (2015), ${ }^{[4]}$

Most of the incidence of sexual assault 36(38.71\%) took place in Victim's Residence, while 31(33.33\%) cases took place in Offender's Residence. This observation is also similar to the finding of Schiff $(1973)^{[16]}$ and Mukhopadhyay (2009) ${ }^{[11]}$ but contrary to Roy Chowdhury $(2008)^{[14]}$ and Tamuli $(2013)^{[20]}$ who reported places other than victim's residence.

The most vulnerable time was between 6:01 PM to 12:00 midnight and between 12:01 PM to 6:00 PM consisting of $39(41.94 \%)$ and $37(39.78 \%)$ cases respectively similar to Schiff $(1973)^{[16]}$ and Das (2009). ${ }^{[6]}$ Maximum number of cases occurred in the season of Summer and Autumn which are consistent with the findings of Tamuli $(2013)^{[20]}$ but inconsistent with Memchoubi $\mathrm{Ph}(2013)^{[8]}$ have found in his study that maximum incidence occurred during FebruaryApril.

Maximum numbers of cases were brought within 3 days of incident of alleged sexual assault. $42(45.16 \%)$ of cases were brought for medical examination within 24 hours of incident. These findings are consistent with the findings of Santos et al (2006). ${ }^{[15]}$

Most of the offenders of sexual assault cases were known to the victims consistent with the findings of Bhowmik
$(2011)^{[5]}$ and Tamuli (2013) ${ }^{[20]}$ but was in contrast to Schiff (1973). ${ }^{[16]}$ Maximum cases - $58(62.37 \%)$ had attained Menarche and $2(2.15 \%)$ cases attained Menopause. Rest 33 (35.48\%) cases have not attained Menarche which are consistent with the findings of Roy Chowdhury (2008) ${ }^{[14]}$ and Tamuli (2013). ${ }^{[20]} 1(1.08 \%)$ victim was pregnant similar to Bhowmik (2011) ${ }^{[5]}$ and Tamuli (2013). ${ }^{[20]}$ Stains on the cloth were present only in $11(11.83 \%)$ cases out of which 2 were blood stains and rest were seminal stains, similar to Das (2009). ${ }^{[6]}$

Maximum number of cases 59(63.44\%) had injuries either in genitalia or body or in multiple parts of the body while $34(36.56 \%)$ cases had no such injuries present. $25(26.88 \%)$ cases had injuries over genitalia. These findings are consistent with the findings of Voight (1972), ${ }^{[19]}$ Mishra $(1981)^{[10]}$ and Santos (2006). ${ }^{[16]}$ Most of the victims 56 $(60.22 \%)$ had hymenal tears and $37(39.78 \%)$ had Intact Hymen. 35 (37.64\%) cases had old tears and 15(16.13\%) had Carunculae Myrtiformes. Recent tear was seen in only 6 $(6.45 \%)$ cases. Out of 50 victims with old tears, 1 case had associated redness and tenderness and out of 37 victims with intact hymen 11 cases had associated redness and all of them were minors.

In the present study $6(10.71 \%)$ cases had recent tear associated with redness, tenderness and bleeding. Amongst the adolescent victims many of them had old tear in the hymen. These findings are consistent with the findings of Tamuli (2013) $)^{[20]}$ and Baruah (2015) ${ }^{[4]}$ who also found that percentage of victims with old tears were more than victims with recent tear and intact hymen. However, in contrast Roy Chowdhury (2008) ${ }^{[14]}$ found that maximum percentage of victims presented with recent tears.

$21(22.58 \%)$ cases had tears in 6 O'clock position which was most common.12 O'clock position was the least common with no tears at all. In most of the cases tears were seen in multiple positions which are consistent with the findings of Tamuli (2013) ${ }^{[20]}$ and Baruah (2015). ${ }^{[4]}$ In the present study $5(5.38 \%)$ cases showed presence of spermatozoa and 8 $(8.60 \%)$ cases showed the presence of RBCs in the microscopic examination of vaginal smears/vulval/oral/anal swabs consistent with the findings of Mishra et al (1981) ${ }^{[10]}$ but differs with Schiff (1978). ${ }^{[17]}$

\section{Conclusion}

The entire gamut of increasing crime, less reporting rate of the same to the authorities and the pitiable low conviction rate, have become a cause of grave concern in the civilized society. Health professionals have a large role to play in delivery of justice by supporting victims of sexual assault medically and psychologically and collecting evidence to assist prosecutions as mandated by the laws of the land, careful analysis of evidentiary exhibits in addition to rehabilitation. A multidisciplinary approach encompassing 
criminal justice functionaries, medical and forensic care, sophisticated forensic laboratories, nongovernmental organizations, media and even the common man have to coordinate to ease the multitude of agonies faced by the female survivor of sexual assault.

\section{Suggestions}

1. To organize seminars and workshops and sensitize judiciary, police officers, para medical staff and Non-governmental organizations as to handling sexual assault cases medico legally. 12

2. Implementation of sex education, Committees Against Sexual Harassment (CASH) and helpdesks at educational and occupational institutions.

3. Educating every woman about their rights and providing counseling, assistance, safety and rehabilitation to victims and family members including creation of awareness among women in particular and public in general to the protocols of cases of sexual assault.12

4. More concerted effort on part of family, community, media sources and law enforcing agencies to report domestic violence.

5. Inclusion of strict punishment for false charge by petitioner or misuse of the law by the respondent and further amendment by addition of a separate sub-clause for the elderly women.

\section{Bibliography}

[1] Angam G., Memchoubi Ph., Nabachandra H. Purity defiled: How safe is your child? A study of child victims of sexual assault in Imphal during 2001-6. J Forensic Med Toxicol. 2006; 23(2):7-11. (35)

[2] Aggrawal A. Medico-legal Aspects of Sexual Crimes and Unusual Sexual Practices. 1st Ed. New York: CRC Press; 2009: p202, 203, 204, 213, 214. (96).

[3] Bass, A. An Investigation of Hindu Scripture. Apologetics Press [On-line]. Available from: http://www.apologeticspress.org/articles/2580.(6)

[4] Baruah AM, Haflongbar S, Chaliha R. A statistical analysis of alleged victims of sexual assault: a retrospective study. Inter $\mathbf{J}$ of Medico-legal Update July 2015;15(2):81-85.

[5] Bhowmik K, Chaliha R. A descriptive one year study on the alleged male and female victims and accused of sex crimes. J Indian Acad Forensic Med 2011;33(3):214-220

[6] Das PP. A study of alleged rape victim cases in Kamrup district, Assam. (Thesis submitted to Gauhati University for Degree of Doctor of Medicine of Forensic Medicine) 2009.
[7] Gradwohl (1976): Gradwohl's Legal Medicine, 3rd Ed. Editor Fracis E. Camps, Completed by Ann, E. Robinson of Bernard, G.B. Lucus Evistol, Sohn wright and sons Ltd.

[8] Memchoubi Ph., Singh P.K., Keisam S., Nabachandra H.; Rape or Pseudo Rape: A Five Year Study of the Medico-legal Cases in Imphal. J Indian Acad Forensic Med. 2013,.35(3) 242-244

[9] Mohanty N. K. and Das. R.; Rape: difficulties in diagnosis. Paper presented in the Ann. Conf. of IAFM.

[10] Mishra S., Bhanot M.L.; Criminality amongst women in India. A study of Female offenders and female victims. Police Research \& Develop. Qr. III, 1981, p. 1-14.

[11] Mukhopadhyay P.P. and Singh O.; Psychiatric assessment of victims of sexual assault: A preliminary study from Burdwan Medical College, Burdwan, West Bengal; J Indian Acad Forensic Med. 2009; 31(3): 237-242.

[12] Naidu TKK. Medico legal aspects of crime against women. J Indian Acad Forensic Med 2008;30 (4):255-8.

[13] O'Toole, Laura L.; Schiffman, Jessica R., (1997). Gender Violence: Interdisciplinary Perspectives. p. 235. (87)

[14] Roy Chowdhury UB, Bose TK, Prasad R. Rape: its medico-legal and social aspect. J Indian Acad Forensic Med 2008;30 (2);69-71.

[15] Santos J.C., Neves A. Rodrigues M., Ferrao P. Victims of sexual offences: Medicolegal examinations in emergency settings. J Clin Forensic Med 2006 Aug; 13(6-8):300-303. (51,60)

[16] Schiff AF. Statistical features of rape. J Forensic Sci 1973; 14:102.

[17] Schiff AF. Reliability of the acid phosphatase test for the identification of seminal fluid. J Forensic Sci 1978 Oct;23 (4):833-44.

[18] Sukul B., Chattopadhyay S. and Bose T. K. A Study of the Victims of Natural Sexual Offence in the Bankura District in West Bengal. J Indian Acad Forensic Med. 2009; 31(1); 25-29. (27,67)

[19] Voight J. Sexual offences in Copenhegam: a medico-legal study. Forensic Sci 1972 Apr;1 (1):67-76.

[20] Tamuli RP, Paul B, Mahanta P. A statistical analysis of alleged victims of sexual assault: a retrospective study. J Punjab Acad Forensic Med Toxicol 2013;13 (1):7-13.

[21] The Hindustan Times (1997) Delhi's shame: Women most unsafe, Delhi, p4. Retrieved on 201408-27 (39) 
International Journal of Innovative Research in Medical Science (IJIRMS)

Volume 03 Issue 07 July 2018, ISSN: 2455-8737, Imp. Factor - $\underline{4.102}$

Available online at $-\underline{\text { www.ijirms.in }}$

$\underline{\text { Graphs }}$

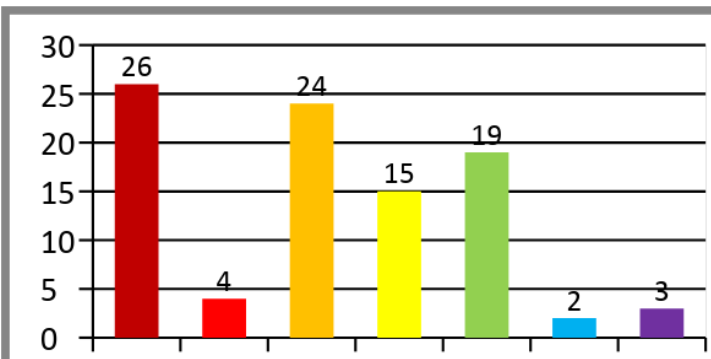

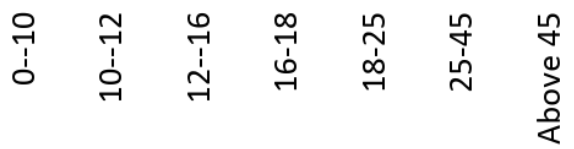

Graph-1 Age wise distribution

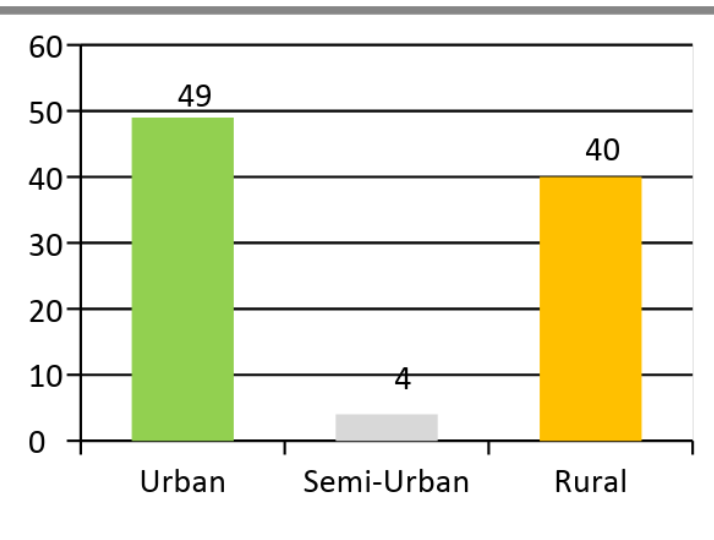

Graph-3 Locality
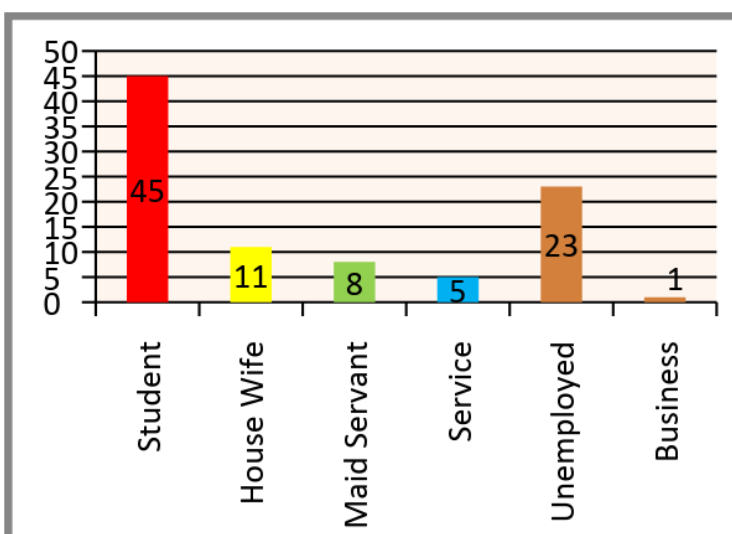

Graph-5 Occupational status

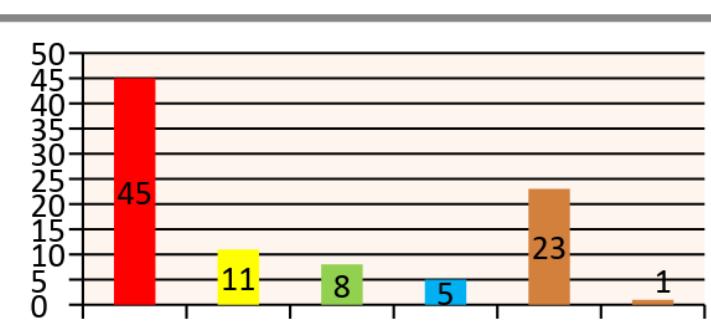

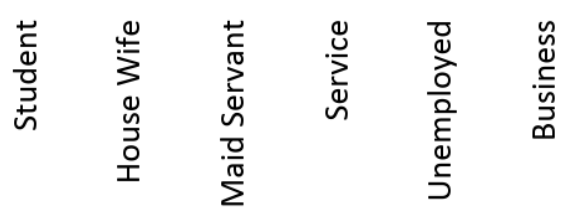

Graph-5 Occupational status

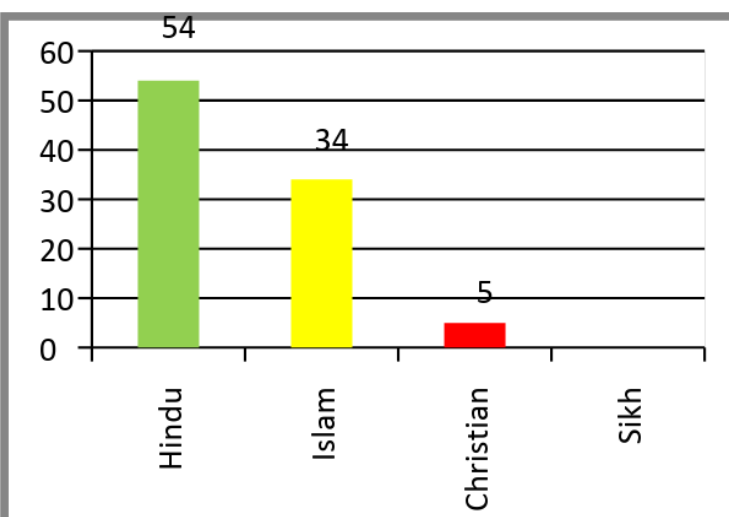

Graph-2 Religion

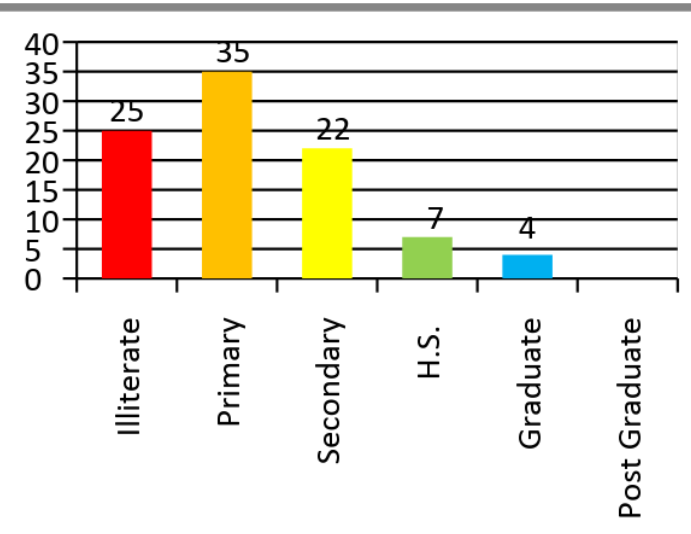

Graph-4 Educational status

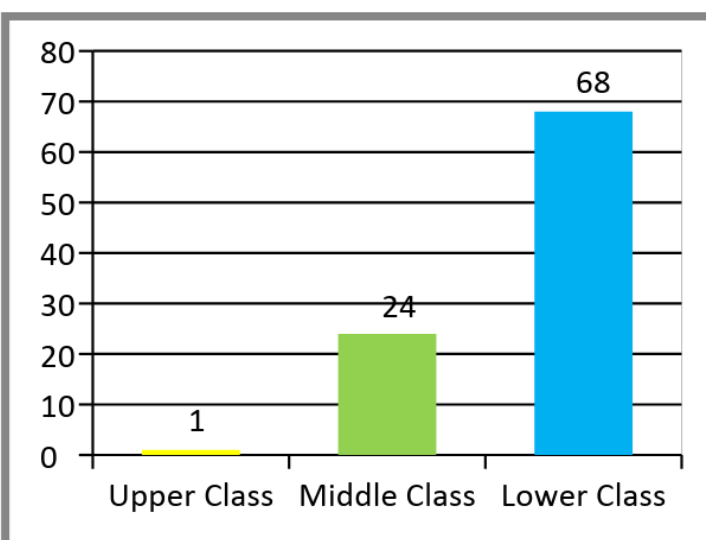

Graph-6 Socio-economic class

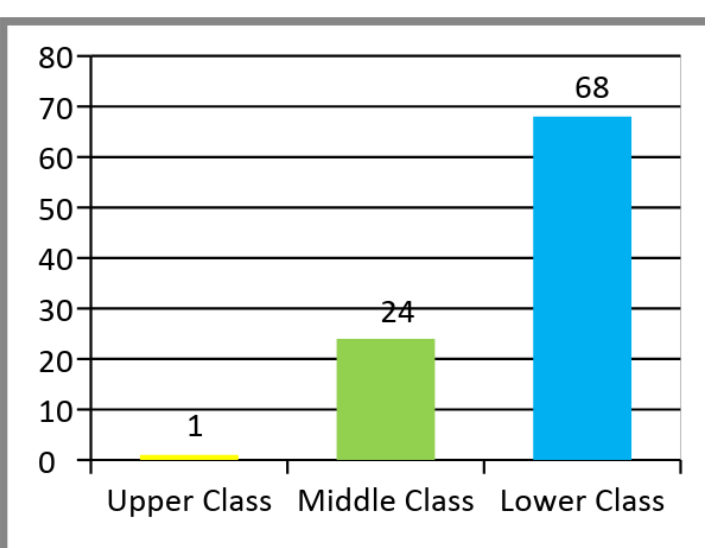

Graph-6 Socio-economic class 
International Journal of Innovative Research in Medical Science (IJIRMS)

Volume 03 Issue 07 July 2018, ISSN: 2455-8737, Imp. Factor - $\underline{4.102}$

Available online at $-\underline{w w w . i j i r m s . i n}$

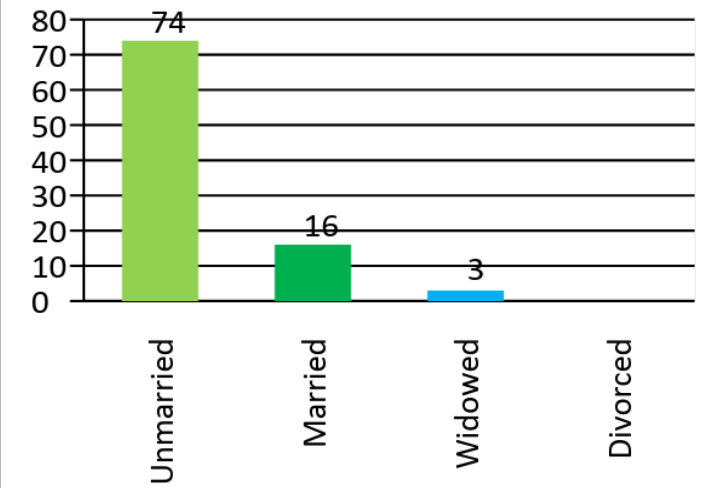

Graph-7 Marital status

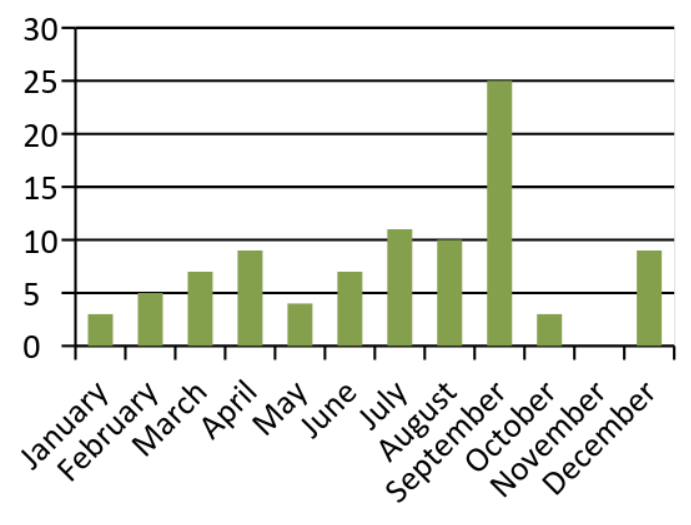

Graph-9 Monthwise variation

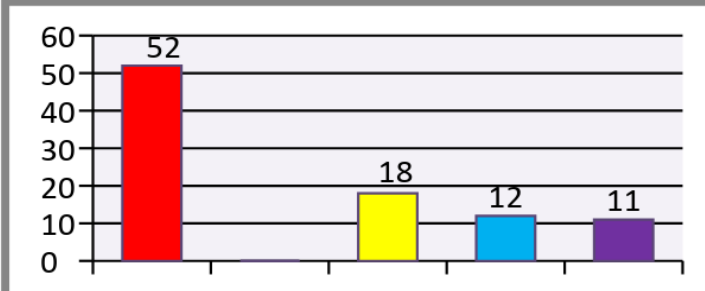

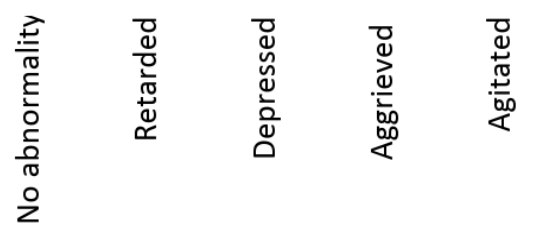

\section{Graph-8 Mental status}

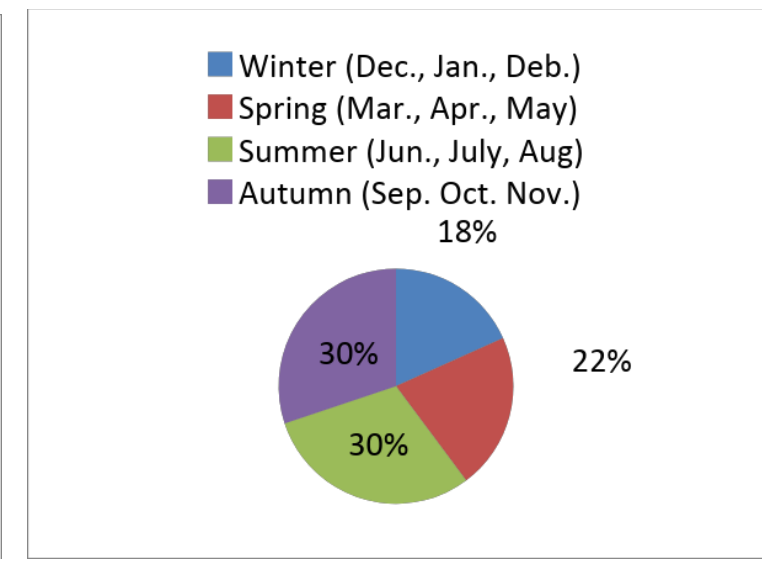

Graph-10 Seasonal variation

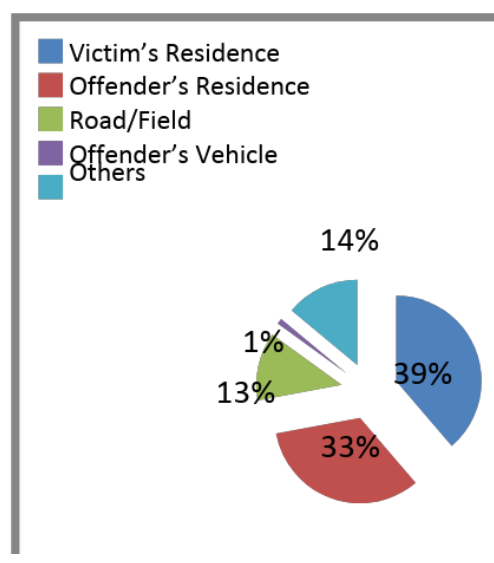

Graph-11 Place of incidence

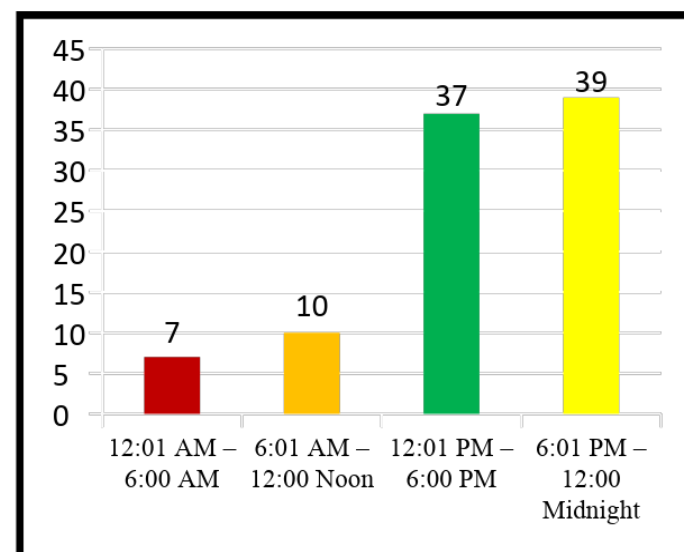

Graph-12 Duration of the day

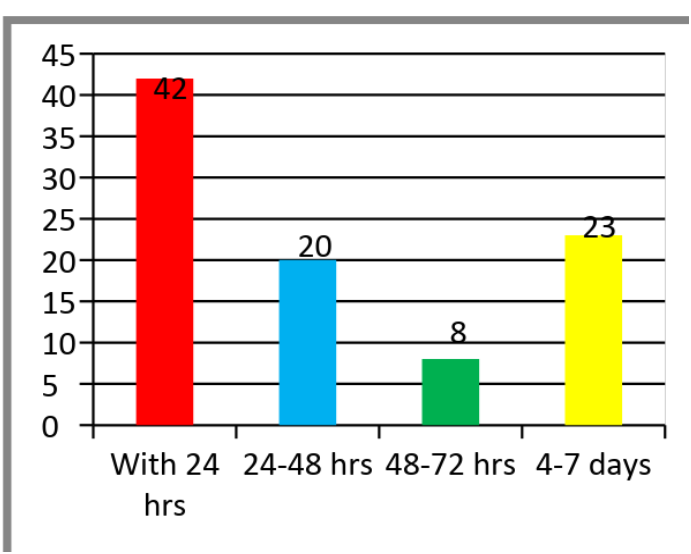

Fig-13 Interval between incidence and examination 
International Journal of Innovative Research in Medical Science (IJIRMS)

Volume 03 Issue 07 July 2018, ISSN: 2455-8737, Imp. Factor - $\underline{4.102}$

Available online at $-\underline{\text { www.ijirms.in }}$

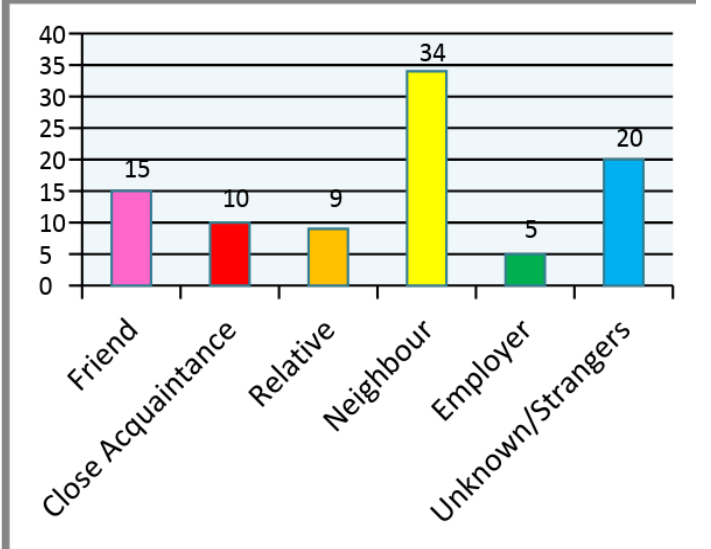

Fig-14 Victim offender relationship

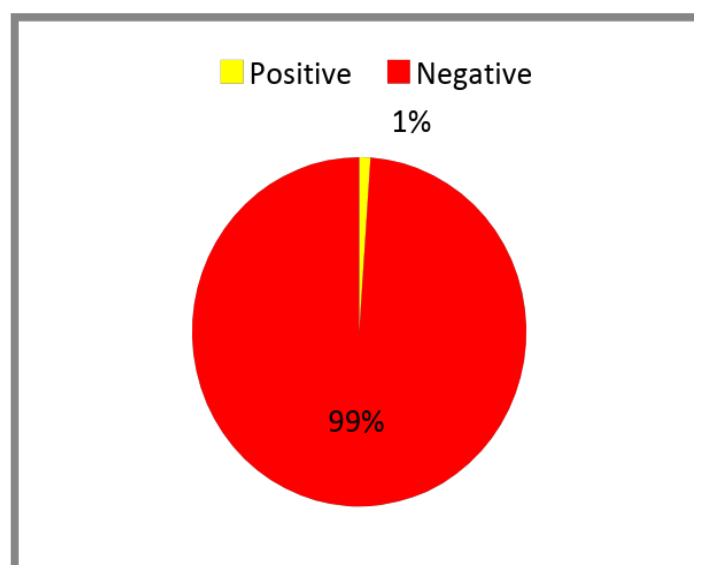

Graph-16 Pregnancy status

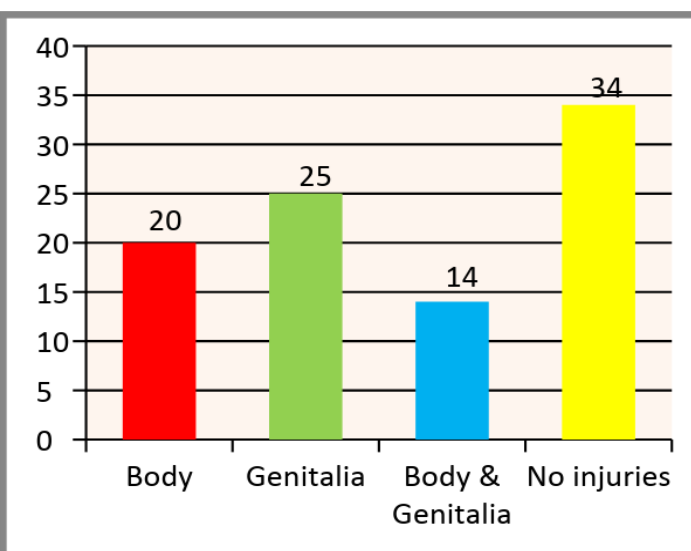

Graph-18 Physical injuries

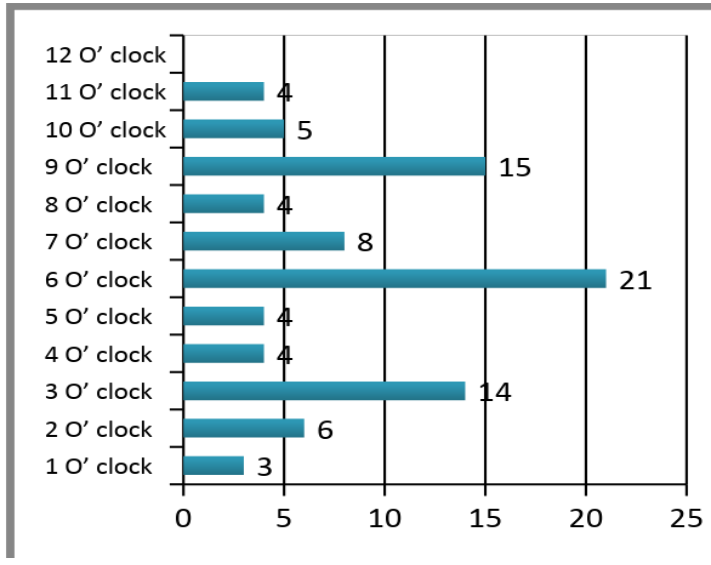

Graph-20 Clockwise tear of hymen $\square$ Menarche $\square$ Menopause $\square$ Not Attained

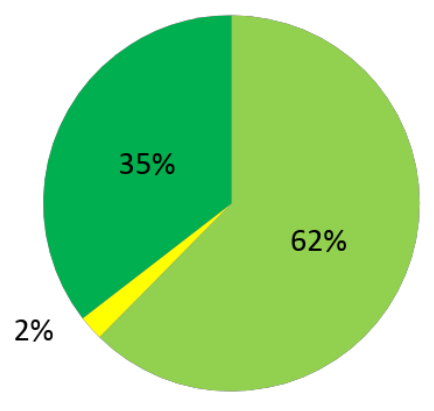

Graph-15 Menstrual history

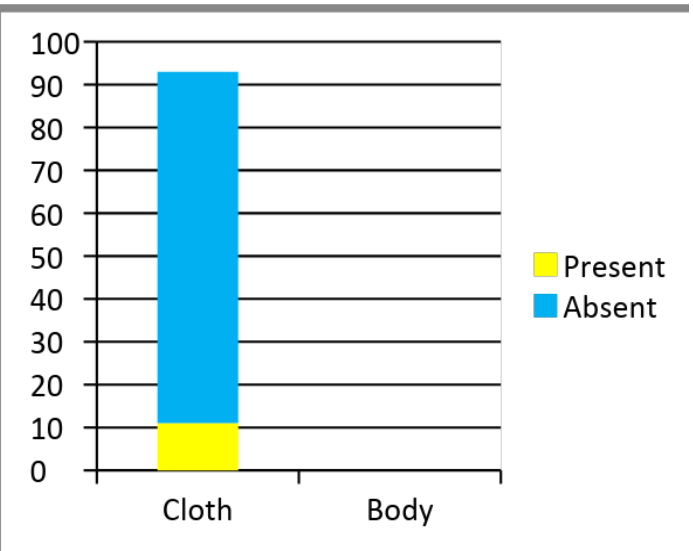

Graph-17 Stain on body and clothes

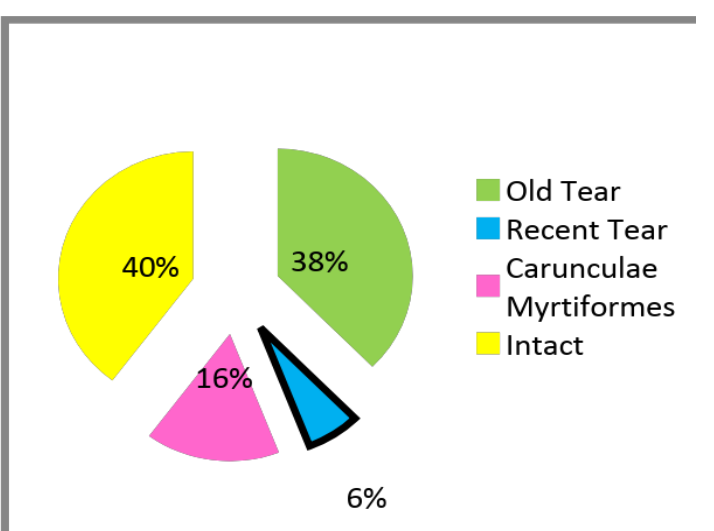

Graph-19 Types of Hymenal tear

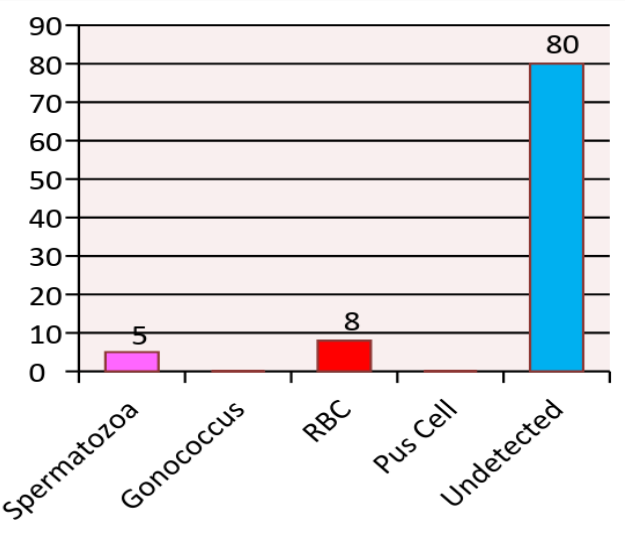

Graph-21 Laboratory findings 